tube inserted in order that after the plastic operation the parts might be kept entirely free from the contact of urine. From this time forth the boy lived night and day in a warm boric bath, a procedure which 1 do not doubt contributed largely to the success of the operation as well as to his own comfort. The perineal tube answered admirably and he never complained of it. The plastic operation was undertaken on May 20th and presented no difficulties save such as were entailed by formation of the urethra and accurate suturing. The urethral flap having been freed from the corpora cavernosa on which it lay was moulded into a tube upon a catheter, fine catgut being used for the sutures. The corpora cavernosa were separated from each other with singular ease, and their subsequent union, together with the fixation of the new urethra in its rightful place beneath them, was made with finest silk. Finally, the skin along the whole length of the penis and over the infundibuliform opening was sutured with silkworm gut. A soft catheter was then passed by the natural route into the bladder, secured, and left there. Everything went well after the operation, but on May 24th there was so much œdema of the scrotum that I made several punctures in it, the perineal tube was removed, and one or two of the dorsal silkworm stitches were taken out because of obvious tension. The soft catheter was also taken out, cleaned, and re-inserted. More sutures were removed on May 26th and by June 1st the perineal wound was healed. Already the child had gained considerable control over the passage of the urine and emptied his bladder at will through the retained catheter. He was still kept in the bath. By June 8th the retained catheter was discarded and the urine was drawn off twice a day, not with the object of emptying the bladder, but of obviating a tendency to contraction at the meatus. Removal of the boy from the bath for a few hours revealed slight leakage at the infundibulum, and accordingly on June 18th a small plastic operation, which need not be specially described, was undertaken for the closure of the tiny orifice which was alone the cause of it. This was successful, and after a few days longer in the bath the child was recorded on July 1st as being able to retain his urine for seven hours, as passing it naturally, and as being perfectly dry throughout the day. When discharged on July 7 th it was noted that he was able to retain his urine all night and the only defect, if so it may be called, in the result of the operation was a slight tendency to contraction of the meatus, for which the daily passage of a catheter was recommended. The latest reports of his condition are in every way favourable and he is now regularly at school.

It may be said that the result of the operation far exceeded our expectations, and while but small experience can be gained from one case only I feel nevertheless that the record of it may be of use in calling the attention of surgeons to an operation of unquestionable value for the treatment and cure of a malformation so grievous and distressing as that of complete epispadias.

\section{SOME MALFORMATIONS MET WITH IN THE POST-MORTEM ROON.}

\section{By CHARLES POWELL WHITE, M.B. CANTAB.} F.R.C.S. ENG.,

DEMONSTRATOR OF PATHOLOGY AT THE YORKSHIRE COLLEGE, LEEDS FORMERLY PATHOLUGIST TO THE GENERAL HOSPI'AL, BIRMINGHAM.

Duning the eighteen months from March, 1897, to September, 1898, when I was pathologist to the General Hospital, Birmingham, I noticed several malformations which are worthy of being placed on record. The number of post-mortem examinations cluring that period was 394 .

\section{Monsters}

Anencephalus.-There was one anencepbalic monster which presented the usual features.

Sympus.-There was one "siren monster" of the variety sympus dipus. It was a full-term foetus and the upper part of the body was perfectly well formed. The lower limbs were united as far as the bases of the little toes, the union consisting of skin and subcutaneous tissue. There was no anus and the external genitals were represented by a semieircular tag of skin $\frac{3}{8}$ in. in diameter. There were many malformations of the viscera, which will be noticed under their respective headings.

\section{HEART AND BLOOD-VESSELS.}

Absence of pericardium.-There was one instance of this very rare anomaly. It was in an adult woman who died from septic peritonitis following on suppurating ovaries. The heart lay in contact with the base of the left lung, the serous membrane passing directly from the base of the heart on to the root of the lung. On lifting up the heart a trace: of the division of the pleuro-pericardial cavity into two could e seen in the form of a fold extending from the lower left pulmonary vein to the diaphragm just to the left of the nferior vena cava. This fold projected $\frac{3}{8}$ in. into the cavity. The left phrenic nerve passed along the front wall of the cavity behind the sternum in front of the aorta and right auricle, and reached the diaphragm at the same point as the fold above mentioned; it then passed along the upper surface of the diaphragm and entered its substance at the usual place. The heart itself was normal.

Deficiency of inter-ventricular septum.- This was in a male aged twenty-three years, who died from acute phthisis. The right ventricle was enormously hypertrophied, the left being much smaller than usual. The deficiency was at the upper part of the septum, the aorta appearing to arise equally from both ventricles. The foramen ovale was closed and the aortic and pulmonary valves were normal. There was no stenosis of the pulmonary artery. The ductus arteriosus was patent.

Deficiency of the aortic valve. - In one case the aortic valve consisted of two curtains only, both coronary arteries arising from behind one curtain. Both curtains were the seat of recent infective endocarditis.

Excess in number of eurtains of the pulmonary valve.-In one case there were four curtains in the pulmonary valve. The extra curtain was situated anteriorly and to the right and was smaller than the other three, which were equal in size. All the curtains were healthy and well formed.

Malformation of the tricuspid valve.-In one heart the tricuspid valve presented an unusual malformation. In the middle of the posterior curtain there was an aperture $\frac{1}{4}$ in. in diameter. This aperture was provided with two small curtains to which were attached chordæ tendinex, which arose from the inter-ventricular septum. The valve wasi apparently quite competent.

Left superior vena cava.-In the "siren monster" the left innominate vein ended in the coronary sinus of the: heart.

Persistence of the left posterior cardinal vein.-In this case, which was associated with malformation and malposition of the left kidney, the left common iliac vein immediately after the junction of the internal and external veins divided into two. The smaller branch pursued the ordinary course and the larger passed under the left common iliac artery and passed upwards on the left side of the spine. At the level of the third lumbar vertebra this latter vein gave off a communicating branch to the inferior vena cava which passed behind the aorta. It then passed into the thorax and continued as the hemiazygos vein, which was very large. At the level of the disc between the third and fourth lumbar vertebræ this vein received a large tributary which, originating in the left phrenic vein, received in its course the left suprarenal, ovarian, and renal veins. There was another renal vein which passed over the left common iliac artery to enter the inferior vena cava at its commencement.

\section{ALIMENTARY SYSTEM.}

Duodenal pouches.-In one case (an adult female) the duodenum presented two distinct pouches. One of these was situated at the site of the papilla, the pancreatic and common bile-ducts opening into it; it was $\frac{1}{4}$ in. deep. The other was just above this on the posterior wall of the duodenum and just below the opening of the accessory duct. of the pancreas; it was $\frac{3}{4}$ in. deep and would admit the: index finger.

Meckel's diverticulum.-This anomaly occurred four times. In each case it was situated between $2 \mathrm{ft}$. and $3 \mathrm{ft}$. above the ileo-cæcal valve. The diameter was about 1 in. and the length varied from 1 in. to $2 \frac{1}{2}$ in.

Absence of rectum.--Absence of the rectum and anus occurred in the "siren monster," the sigmoid flexure ending at the brim of the pelvis in a blind extremity.

Imperforate anus. - This occurred twice. In one there was no anal invagination and the rectum terminated close to the 
skin. In the other the rectum terminated at the tip of the coccyx and was separated from the anal invagination by a thin membranous septum.

\section{Genito-URINART System.}

Absence of genito-urinary apparatus. - In the "siren monster" there was no trace of kidneys, ureters, bladder, urethra, or genital glands.

Defective development of one kidney.-In one case the left kidney was represented by a little mass of connective tissue in which the microscope failed to reveal any renal tissue. The renal vessels were represented by a minute artery and vein passing into this tissue. The ureter, which was only pervious for 1 in. at its lower extremity, could be traced upwards as a fibrous cord which was lost in the mass of tissue.

Horseshoe kidney. - Three cases of horseshoe kidney occurred, the union in all consisting of true renal tissue ; each had two ureters. The vessels were normal in two of them and abnormal in the third.

Malformation and malposition of kidney.-In a boy, aged seventeen years, who died from phthisis, the left kidney was large, weighing $5 \mathrm{oz}$; the hilum was placed anteriorly. It was in the normal position. The right kidney was in the right iliac fossa and was circular in shape. Viewed from the front it had the appearance of two kidneys, one above the other, with their hila adjacent. The pelves of the two halves were distinct and were united by a canal of the size of a ureter which was $\frac{1}{2}$ in. long ; the ureter arose from the lower pelvis and passed in front of the lower half. Posteriorly the kidney presented a uniform surface except for a transverse sulcus, in which ran an artery. Each half of the kidney had its own vein, which entered the inferior vena cava. There were two renal arteries arising from the aorta just above the bifurcation; one passed to the front and divided into two, one branch going to each half. The other passed along the sulcus at the back of the kidney and after giving off branches into its substance passed round the outer edge to end in the outer side of the hilum. This kidney weighed $5 \mathrm{oz}$. The suprarenal body was in the normal situation.

Another case similar to this occurred in a woman, aged forty-four years. It was associated with the persistent cardinal vein above mentioned. The right kidney was normally placed and was normal in size and structure. The left kidney was in the left iliac fossa and resembled the last one almost exactly except that there was one pelvis common to the two halves. One artery arose from the aorta just above the bifurcation and passing to the back of the kidney entered a transverse sulcus in which it passed to the outer edge, round which it turned to end in the outer side of the hilum. Another artery arose from the sacral aorta and passing in front of the left common iliac artery entered the hilum from the front.

Uterus bicornis. - One case of uterus bicornis was recorded. The two horns were $\frac{1}{2}$ in. long. The cervix and the main part of the body of the uterus externally appeared single. There was a septum in the body of the uterus dividing it into two halves. The cervix and the vagina were single.

I am indebted to the honorary staff of the hospital and to Mr. W. E. Bennett for permission to publish these notes.

\section{THE OCCURRENCE OF RHEUMATISM IN CHILDREN SUBSEQUENT TO AN ATTACK OF CHOREA.}

BY FREDERICK E. BATTEN, M.D. CANTAB., M.R.C.P. LOND.,

ASSISTANT PEYSICIAN TO THE HOSPITAL FOR SICK CHILDREN, GREAT ORMOND-STREET.

ON the occurrence of rheumatism previously to the onset of chorea numerous tables have been compiled and among the more recent an analysis of 327 cases by Fletcher ${ }^{1}$ showing that 26 per cent. of cases suffer from rheumatism previously to the onset of chorea. His figures agree closely with those of S. Mackenzie, who gives 29 per cent., and the majority of observers place the percentage between 25 per cent. and 30 per cent., only Sturges places it as low as
20 per cent., and Sée and Hughes at 48 per cent. and 65 per cent. respectively.

Some time ago, at the suggestion of Dr. Lees that it would be of interest to find out what percentage of choreic children subsequently develop rheumatism, the following analysis was made of cases of chorea discharged from two wards of the Hospital for Sick Children, Great Ormondstreet, under the care of the late Dr. Sturges and Dr. Lees during a period of two and a half years-viz., from January, 1892, to June, 1894. During this period 115 cases wese discharged from the hospital. Of these 115 cases, in 78 (67.8 per cent.) there was no history of previous rheumatism, while in the remaining 37 (32.2 per cent.) there was some evidence of the patient having previously suffered from rheumatism. The chart shows the age and sex of the children affected.

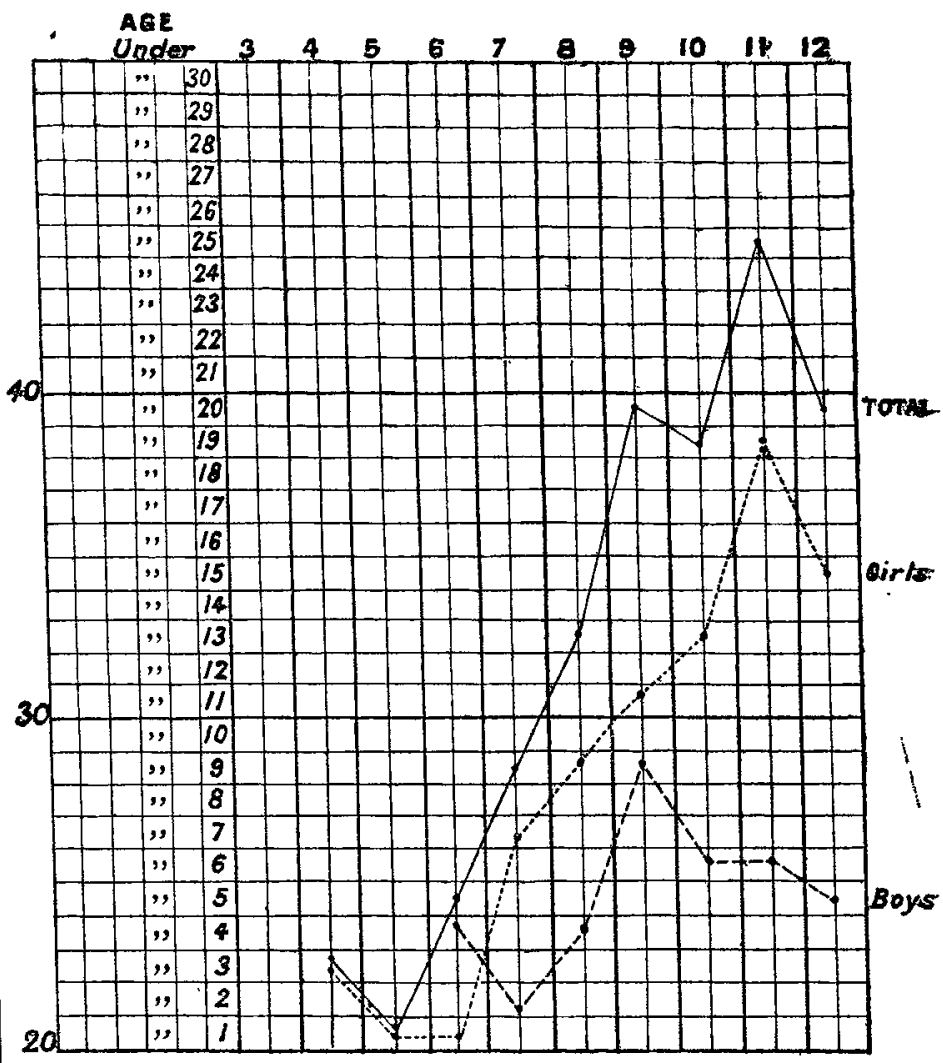

The abscissæ show the number of children and the ordinates the ages of the same. The dotted line shows cases in girls and the broken line cases in boys.

In July, 1895-i.e., a year after the last patient and more than three years after the first patient had left the hospitalpostcards were sent to these 78 cases requesting that they would attend the hospital, or, in some cases where the distance was great, that they would reply to certain questions by postcard. Of these 78 cases, 34 were examined and 23 replied by letter, a total of 57 cases; 19 gave no reply; 2 had died, 1 from scarlet fever and 1 from meningitis. Of these 57 cases there was evidence of rheumatism in 11 ; in 2 others, although there was no history of rheumatism, nodales were present and well-marked cardiac lesions, and this I consider a deñnite rheumatic manifestation, although at variance with a statement of Osler in his book on Chorea, p. 16-i.e., 13 cases in all. of the above 13 cases 2 had attacks of pericarditis with rheumatism and were treated in the hospital, the first after the third attack of chorea and the second six months after the first attack of chorea. Thus $11 \cdot 3$.per cent. of cases without previous rheumatism developed rheumatism within three years.

In July, 1898 (three years later), cards were sent to 44 out of the 57 cases-i.e., to all those who had not had rheumatism up to July, 1895-and from whom a reply had been previously obtained. Of these 44 cases 29 were either seen or heard from. Of these 29 cases 18 had had no rheumatism ; 10 had had rheumatism ( 4 cases were designated as rheumatic fever and 6 cases as rheumatism); and 1 had died from heart disease in the London Hospital. That is to say, there was evidence of rheumatism in 11 of the 29 cases, a further increase of 9.7 per cent., making a total of 20 per cent. within six years. Whipham ${ }^{2}$ found that chorea pre ceded rheumatism in less than 2 per cent. of all cases, while in the present series the percentage amounted within three 